\title{
SAÚDE MENTAL E INTENSIFICAÇÃO DO TRABALHO: REFLEXÕES SOBRE METAS E PATOLOGIAS LABORAIS
}

\section{ARTIGO ORIGINAL}

OLIVEIRA, José Fernando Lima de ${ }^{1}$, BUENO, Hellen Paola Vieira²

OLIVEIRA, José Fernando Lima de. BUENO, Hellen Paola Vieira. Saúde mental e intensificação do trabalho: reflexões sobre metas e patologias laborais. Revista Científica Multidisciplinar Núcleo do Conhecimento. Ano 06, Ed. 09, Vol. 03, pp. 157172. Setembro de 2021. ISSN: 2448-0959, Link de acesso: https://www.nucleodoconhecimento.com.br/psicologia/intensificacao-do-trabalho, DOI: 10.32749/nucleodoconhecimento.com.br/psicologia/intensificacao-do-trabalho

\section{RESUMO}

Questão problema: A presente pesquisa discute o adoecer mental no ambiente laboral frente a intensificação do trabalho, contextualizando o panorama de competitividade em organizações empresariais na atualidade, ou seja, como a intensificação do trabalho, a partir das metas laborativas pode afetar a saúde mental do trabalhador? Objetivo: O objetivo principal desta pesquisa foi de debater acerca do ambiente laboral atual inserido na competitividade de mercado, marcado pelas pressões por produção e excessivas jornadas de trabalho, discutindo-se assim o adoecer mental dos trabalhadores. Discute-se ainda a relação de acúmulo de capital como vertente desta intensificação do trabalho e o temor do trabalhador ante a incapacidade em cumprir as obrigações e o processo de vulnerabilização e violência laboral, bem como o posicionamento das organizações empresariais frente ao processo de adoecer. Metodologia: Utilizou-se nesta pesquisa, uma abordagem metodológica de revisão bibliográfica, cujos referenciais teóricos foram de Marx a Dejours, passando por Foucault. Principais resultados: ressaltamos o momento atual

\footnotetext{
${ }^{1}$ Graduado em psicologia pela Universidade Potiguar, pós graduado em saúde mental pela UCDB e aluno de mestrado em educação pela UDE/UY.

${ }^{2}$ Orientadora.
}

RC: 97019

Disponível em: https://www.nucleodoconhecimento.com.br/psicologia/intensificacaodo-trabalho 
como marcado pela desumanização das relações de trabalho e pelo processo de adoecimento, acreditando assim ter contribuído para o debate sobre as questões de qualidade de vida no trabalho, evidenciando a necessidade de atenção à problemática tão presente no ambiente laboral.

Palavras-Chave: Saúde mental, Trabalhadores, Intensificação do trabalho.

\section{INTRODUÇÃO}

$\mathrm{Na}$ atualidade a humanidade vem passando por profundas mudanças, interferindo diretamente na forma como se interage em sociedade. O século XX e início deste novo século, tem se configurado por essas transformações tecnológicas que atingiram as organizações, notadamente nas relações sociais no ambiente laboral. Essas transformações, vieram para trazer crescimento da economia, aumento da produtividade organizacional e expressivo acúmulo de capital. Percebe-se que a lógica de produção permanece a mesma, que outrora vigente, nas relações capital/trabalho, assim como no século XIX, revisitando a arrecadação da riqueza produzida pelas camadas sociais e dos elementos naturais, corroborando o mercado como ápice ou eixo da sociedade. Diante de tais problemas, o tempo, a intensificação do ritmo de trabalho e a crescente desvalorização do humano frente ao capital alavancam a concorrência nas organizações, aumentando exponencialmente, obrigando ainda as organizações empresariais a pesquisarem diferenciais no afã de se destacarem ante ao mercado globalizado, cada vez mais competitivo. Neste processo, a tão sonhada "vantagem competitiva" transforma-se em mediadora dos objetivos organizacionais. "A vantagem competitiva surge fundamentalmente do valor que uma empresa consegue criar para seus compradores e que ultrapassa o custo de fabricação pela empresa" (POTER, 1989, p. 2).

Neste novo mundo, o desenfreado buscar do acúmulo de capital, puxado pelo desenvolvimento da tecnicidade, as organizações empresariais, paulatinamente, sobem suas exigências frente às capacitações dos trabalhadores, requerendo 
destes ainda mais habilidades, agilidade e que estes saibam acompanhar as atualidades, ainda que a função pretendida seja o mais básica possível. Ante o competitivo mercado, numa velocidade cada vez mais difícil de se acompanhar, as exigências das organizações e as necessidades sociais, tem se transformado numa complexa problemática da atualidade. Exemplo disto, os avanços tecnológicos que viriam para auxiliar a dinâmica organizacional, prestando uma melhor qualidade de vida ao homem, na verdade acabam por mostrar o outro lado da moeda. No contrapasso desta evolução e do ritmo de crescimento organizacional, não raras vezes o ônus laborativo tem afetado a saúde dos que empreendem sua força de trabalho, aqueles que sustentam o mercado.

Em paralelo a preocupação do acúmulo de capital, adquire-se um valor de troca, como se todos se convertessem em uma ação de mercado, cujo preço é julgado por outrem. Logo, ao final, o que deveria também beneficiar aqueles que sustentam esse mercado, pela aquisição de conhecimento, dinheiro, bem-estar, acaba por tornar-se a loucura pelo número de páginas do currículo, tudo para o próximo processo seletivo, já que a atual atividade laborativa é apenas uma situação momentânea. (HELOANI e CAPITÃO, 2014)

$\mathrm{Na}$ atualidade, produzem-se aceleradas mudanças tecnológicas nas formas de produção, as quais, consequentemente, afetam os trabalhadores em suas rotinas de trabalho, modificando seu entorno laboral e aumentando o aparecimento ou o desenvolvimento de enfermidades crônicas (CAMELO e ANGERAMI, 2008, p. 238).

Silva (1994) complementa: "os avanços tecnológicos cada vez mais aumentam as exigências cognitivas, determinando esforços mentais sempre maiores" (p. 74).

Exemplificado de outra forma, nota-se que o crescimento econômico das organizações empresariais vêm acompanhado pelo aumento da produtividade, assim a saúde da organização depende, a priori, dos meios de produção, das condições laborais, dos estilos de vida, e, principalmente, da qualidade de vida dos colaboradores. Na medida em que se torna frequente as longas jornadas de trabalho e a intensificação de pressões no ambiente laboral, cria-se a instabilidade na saúde 
do trabalhador. Por consequência da lógica organizacional, pensando o princípio da não estagnação da produção para se colocar acima das necessidades e dos limites físicos e psicológicos dos trabalhadores que mantém as "engrenagens rodando", encaminhando assim a uma nociva prática onde não há descansos, cujas refeições são sacrificadas, os ritmos se aceleram, oriundo das crescentes metas de produção e a jornada se prolonga até que seja sanado o problema que atrapalhou o crescimento.

Neste cenário construído, cabe-nos lembrar da atuação de Charles Chaplin em "Tempos modernos" (1936). Embora a situação encenada pelo ator atribua um valor humorístico, não deixa de criticar, sutilmente, a relação entre o acúmulo de capital nas organizações empresariais, a intensificação do trabalho e as sobrecargas, inerentes à condição de ausência de saúde mental.

Neste sentido, é premente a necessidade de se buscar estratégias que cuidem das variações de problemáticas que são notadamente vistas, justamente pelo fato da insuficiência dos estudos acerca do volume de atividade cognitiva requerida, desconsiderando o tempo na qual incide tal exigência. (SILVA, 1992)

Por fim, nestes comentários iniciais, realizamos breve análise acerca do momento atual das organizações ante as possibilidades humanas. Ressalta-se ainda que não objetivamos realizar um diálogo estreito com a concepção marxista acerca do tempo de produção e da temporalidade na circulação, mas a perspectiva teórica citada acaba por adquirir valiosa contribuição por considerar a possibilidade de se pensar a intensificação do ritmo de trabalho, como uma trivialidade no processo de acúmulo de capital. Ainda assim, a partir desta pesquisa, buscamos apresentar soluções para a questão: como a intensificação do trabalho, a partir das metas laborativas pode afetar a saúde mental do trabalhador?

RC: 97019

Disponível em: https://www.nucleodoconhecimento.com.br/psicologia/intensificacaodo-trabalho 


\section{DESENVOLVIMENTO}

\subsection{A PRESSÃO PELA PRODUÇÃO E O BATER METAS}

$\mathrm{Na}$ atual condição de trabalho, existe a categoria a qual corresponde-se ao trabalho saudável, sendo concebido como vitalizador. Este está correlacionado ao ritmo de trabalho no qual os que vendem sua força de trabalho se apropriam de jornadas de trabalho condizentes com suas necessidades e produzem conforme suas possibilidades. No contrapasso deste ideal de trabalho, sabe-se da condição intensiva, cujas possibilidades de usufruto de bens e direitos são amplamente restritas. Acompanhando este processo, o temor de desarmonizar a produção em relação aos desejos e metas impostas pelas organizações empresariais, intensifica a restrição imposta pela velocidade. (CLOT, 2008)

Obra disto, notamos que os avanços tecnológicos alcançados em todo o planeta, em conjunto com a competitividade do mercado globalizado, acabam por ilustrar o constante processo de produção, predominantemente, estruturado e se movendo pela acumulação de capital e lucro. Neste ritmo de crescimento desenfreado, exemplificado nesta condição intensiva, a sobrecarga de trabalho e a falta de controle sobre as atividades laborais e altos níveis de pressão são concebidos como riscos psicossociais relacionados ao trabalho, que podem levar ao esgotamento, e, por conseguinte, decréscimo do rendimento. "O fato de um indivíduo ser geralmente capaz de lidar com determinada carga de trabalho, por si só, não significa que ele possa sempre caminhar naquele ritmo sem períodos de restabelecimento" (CAMELO e ANGERAMI, 2008, p. 238).

Neste processo contínuo de escalada empresarial, o controle do tempo daqueles que vendem sua força de trabalho passa a ser elemento essencial para a produção, incidindo diretamente no ritmo de produção, reverberando na intensificação do trabalho. Tal fato foi marcado na história pelo stalinismo[3], cujas estratégias para o crescimento, incluíam a supressão do descanso semanal para intensificar ainda mais o trabalho. (LALLEMENT, 2003)

RC: 97019

Disponível em: https://www.nucleodoconhecimento.com.br/psicologia/intensificacaodo-trabalho 
A compressão do tempo e do espaço tal como enunciada por Marx reafirmada por Harvey indica uma aceleração da cadência do trabalho possibilitada pela criação de instrumentos que têm, entre outras, a função de associar disciplina, agilidade e controle dos trabalhadores. No telemarketing, o relógio como parte da ordem social é incorporado aos sistemas informatizados e sintetiza essa perspectiva na organização do trabalho. (VENCO, 2008, p. 7)

Paralelamente ao controle do tempo no ambiente laboral, a definição das metas atende, por exemplo, uma demanda externa num relativo, que verifica um quantitativo "x" de produção, e outro que visa atender a um objetivo interno da contratada, relacionado à necessidade financeira. "Ou seja, a despeito da demanda inicial apontada pelo cliente, a empresa precisa vender mais para ampliar seu faturamento e, com isso, intensifica o trabalho e a pressão sobre os trabalhadores" (VENCO, 2008, p. 10).

Pesquisadores, analisando o controle de tempo nas organizações empresariais de marketing que desenvolviam vendas por telefone, descobriram que mesmo ainda longe da chefia, os trabalhadores sofriam a asfixia do tempo pela tecnologia, logo:

O sistema informatizado mensura cada ligação, como também as pausas para descanso, e assim determina tempos médios de atendimento (TMA). Diferentes dispositivos são acionados sempre que se ultrapassa o TMA. Por exemplo, a emissão de um sinal intermitente na tela, que avisa o operador sobre o tempo excedido. No atendimento receptivo, indica o número de pessoas em fila de espera. Para os trabalhadores, ambos são fatores de tensão, pois, além da pressão exercida pela chefia intermediária, há a da própria máquina. (LALLEMENT apud VENCO, 2008, p. 8)

Da mesma forma, mesmo na ausência da chefia, trabalhadores em funções semelhantes, apresentam o lema internalizado "a produção nunca pode parar" e trabalham sob uma pressão de tempo que é correlata a pressão por produção (VENCO, 2008). Assim o alcance da meta preestabelecida, como o número "x" de mercadorias vendidas ou mesmo " $\mathrm{x}$ " de produtos produzidos, se configura como mais-valia[4] para a organização empresarial, calculada com base nos custos com os que fazem uso das mercadorias.

RC: 97019

Disponível em: https://www.nucleodoconhecimento.com.br/psicologia/intensificacaodo-trabalho 
Frente a estas condições, são prevalentes no histórico de vida de trabalhadores, as manobras organizacionais que nublam as condições humanas e impulsionam o aceleramento da produção, frente às crescentes metas organizacionais estabelecidas. Vale destacar que nesse ritmo voraz de demanda do mercado, as metas são frequentemente alteradas, em função das peculiaridades do produto e das movimentações do mercado. Destaca-se ainda, que o estabelecimento de metas coage os trabalhadores a realizarem suas funções com prazos alienáveis, a mostrar serviço apesar de uma ausência notória de tempo e condições salubres de trabalho.

Nem mesmo fora dos ambientes empresariais os trabalhadores estão imunes a pressão por metas de produção. Na educação, professores se queixam de demasiadas atividades laborais cada vez mais frequentes e em prazos cada vez mais apertados. Teóricos (ASSUNÇÃO e OLIVEIRA, 2014) realizaram uma pesquisa com professores e constataram que estes profissionais estão entre os mais pressionados por metas e tempo atualmente. Segundo estes pesquisadores:

... a professora relatou que diariamente corrige em torno de 32 a 34 cadernos. Para dar conta de tal tarefa, a estratégia adotada pela professora invade sua vida extra trabalho: ela corrige os cadernos no ônibus, enquanto aguarda atendimento em alguma fila e até na hora da "cervejinha". Sua colega é enfática: "Não paro. Da hora em que eu entro, eu não paro na escola... sempre que tenho uma horinha, estou fazendo uma atividade..." (ASSUNÇÃO e OLIVEIRA, 2014, p. 353).

Torna-se notório que a imposição por longas jornadas de trabalho, a intensificação produtiva tem ocorrido em variados campos, que não somente nos ambientes empresariais. Do mesmo modo, pode-se supor que até mesmo encarregados, gerentes e cargos de chefia direta podem sucumbir a tais situações, assim como operários e funções subalternas.

\subsection{O TEMOR E A INCAPACIDADE EM CUMPRIR AS OBRIGAÇÕES}

Diante do cenário acima explicitado, o trabalhador que vivencia um ambiente laboral recheado de pressões por produção, num ritmo acelerado, acaba por caminhar bem

RC: 97019

Disponível em: https://www.nucleodoconhecimento.com.br/psicologia/intensificacaodo-trabalho 
por tempo variável, atingindo o esgotamento de suas capacidades, logo seu desempenho funcional decai e, juntamente com a queda de produção, as cobranças e constantes ameaças à estabilidade funcional. Como observa Linhart (apud BERNARDO; NOGUEIRA e CAPOULADE, 2014):

Cada um vive de modo puramente individual aquilo que constitui uma prova permanente: o medo de não ter êxito, de não estar à altura, de ser pego em desacordo com a qualidade, de desrespeito aos prazos ou de insuficiência de resultados, enquanto pesa uma ameaça permanente sobre o emprego (LINHART apud BERNARDO; NOGUEIRA e CAPOULADE, 2014, p. 88).

Ao mesmo tempo que pesa o temor sobre o baixo rendimento funcional, destoante as metas organizacionais (e suas efetivas consequências) esses trabalhadores têm consciência do ônus físico e mental causado pelo aceleramento do ritmo e constantes cobranças sofridas. Sofrendo os prejuízos das ameaças de emprego, os trabalhadores escolhem continuar no emprego, sacrificando-se assim a sua própria saúde. Numa situação oposta ao trabalho penoso, os trabalhadores se deparam com o desemprego. Assim estes trabalhadores se submetem às condições extremas e insalubres, preterindo o desemprego. (BERNARDO; NOGUEIRA e CAPOULADE, 2014)

Sabe-se ainda, a respeito do presenteísmo ${ }^{[5]}$, considerando os mais subordinados, mesmo adoecidos, ocultam sua condição, não pleiteando benefícios, temendo a perda do emprego logo após o retorno, posterior ao afastamento. Em contraste a isto, boa parte dos trabalhadores que vivenciam ritmo intenso de trabalho não relatam queixas quanto à função que desempenham, se culpando pelos insucessos, atribuindo à sua irregularidade ou à sua falta de responsabilidade ou a não sujeição às condições notadamente ruins. Por consequência disto, agravam sua condição de saúde e, afastados do trabalho por adoecimento profissional, se deparam com dificuldades para a elegibilidade de sua condição de adoecimento tendo origem na atividade laboral. Comumente, as estatísticas da previdência social relatam que os transtornos mentais estão na terceira colocação no ranking na prevalência na concessão de benefícios previdenciários. (TEIXEIRA, 2007)

RC: 97019

Disponível em: https://www.nucleodoconhecimento.com.br/psicologia/intensificacaodo-trabalho 
Reconhece-se entre os principais suplícios sofridos, oriundos do adoecer no ambiente laboral:

O medo, a fadiga acumulada e as perturbações do sono, acrescidos pela percepção da própria queda de desempenho, levam à ansiedade, à irritabilidade e ao mal-estar crescente. É quando, muitas vezes, emergem a autoacusação, a autodesvalorização e vivências de fracasso que configuram o caminho para as depressões e outros transtornos psíquicos e psicossomáticos. O mal-estar continuado atinge - pela via do estresse ou por outros meios - o funcionamento (fisiologia) do organismo e, com o tempo, pode levar a alterações estruturais (enfarte cardíaco, por exemplo). (FRANCO; DRUCK e SELIGMANN-SILVA, 2014, p. 242)

Conjuntamente aos sintomas relatados acima, expressões como, "ritmo alucinante", "trabalho incessante", "loucura”, “desespero", "estresse”, “depressão" são prevalentes nos discursos de trabalhadores quando falam sobre suas atividades laborais no dia a dia. Os principais problemas do trabalho apontados por eles foram o excesso de responsabilidades e o ritmo "insuportável" da produção. Essas situações de intenso ritmo de trabalho foram observadas (VENCO, 2008, p. 2) no telemarketing em face do cumprimento das metas instituídas, no total de contatos, vendas ou negócios fechados, na sua penosidade acabam por desnortear os trabalhadores na percepção de tempo e espaço. Numa provável hipótese deste penoso processo, os trabalhadores acabam por sofrer o decréscimo do rendimento. São sucessivas as quedas de qualidade no trabalho e, por consequência, assim que a ligação ultrapassa o tempo fixado: "começam os insultos e as ameaças de demissão. Os argumentos empregados são sempre os altos índices de desemprego no Brasil e o farto banco de currículos disponíveis na empresa". (VENCO, 2008, p. 7)

Outra forma de opressão sofrida pelos trabalhadores, o constante estado de vigilância aos olhos da chefia, acaba se configurando como mais um elemento de intensificação do ritmo de trabalho. Os gestores atuais de recursos humanos observam que os espaços de vidro, onde são vistos chefia e trabalhadores, mutuamente, representam o lema da empresa, a "transparência nas relações". No entanto, como observa Foucault (1987) em "Vigiar e Punir", tal falácia argumentativa 
oculta à histórica disposição física relacionada aos presídios, promovendo a disciplina e o controle, cujo uso foi notadamente presente nas indústrias no século XX no Brasil e que ainda ressalta o constante processo de vigilância.

Constata-se que atualmente a qualidade de vida do trabalhador que vivencia situações de pressões por metas de trabalho em todas as esferas vêm sofrendo sucessivos ataques no ambiente laboral. Por consequência destes ataques, são deflagradas toda sorte de doenças até então inexistentes no histórico do trabalhador. Comumente as repercussões não estão tão somente restritas as lesões físicas ou orgânicas, mas transtornos mentais vêm se espalhando numa prevalência cada vez maior, ante ao ritmo voraz de produção que oprime e suga todas as forças mentais e físicas do trabalhador.

\section{RESULTADOS E DISCUSSÃO}

Diante do atual quadro de esgotamento físico e mental sofrido pelos trabalhadores, Dejours (1994) afirma que não existe trabalho sem sofrimento. Tal afirmativa traz à tona o esquecido do termo que originou a palavra "trabalho". O referido termo, "tripalium", foi um instrumento de tortura para punições dos indivíduos que, condenados ao ostracismo da sociedade e presos, eram submetidos ao trabalho forçado. Nesta perspectiva, mesmo com o passar do tempo, as condições atuais de mercado, somado ao ritmo de produção, tem resgatado o sentido "original" atribuindo outrora ao trabalho. Assim, a repetição da violência do ambiente de trabalho[6], torna comum as situações de exploração. Em muitos casos, organizações empresariais que fazem uso do jogo de competição interna, ilustrada no quadro de metas e "funcionário do mês", ocasionam a criação de rivalidades entre os trabalhadores, e, por conseguinte, gera-se o processo de coisificação ${ }^{[7]}$ das relações humanas, agravando os riscos à saúde mental. Posteriormente a fragilização do ser humano, frente ao método imposto pela empresa, tende a gerar a perda do sentido de trabalho e a falta de identidade com o trabalho, sofrida pelos trabalhadores (FRANCO; DRUCK e SELIGMANN-SILVA, 2010). 
[...] A maximização da competitividade da própria empresa, repetimos, é a grande finalidade do incremento à excelência. Ao ser transferida para os indivíduos, essa exacerbação da competitividade pode se tornar feroz. Além de incrementar o individualismo, cria também a violência. Para obter o máximo de cada um, estimula-se a onipotência e o narcisismo adormecidos, levantando a crença de que os potenciais individuais são ilimitados, de modo que, além de não mais respeitar a integridade dos demais, o indivíduo deixa de ver os riscos de seu próprio desgaste. (SENNETT apud FRANCO; DRUCK e SELIGMANN-SILVA, 2010, p. 238)

Percebe-se que mesmo este processo de intensificação do trabalho tem gerado desgaste mental, até mesmo nos experientes, causando incalculáveis perdas, expressos no nível da saúde do trabalhador e da produção da empresa. Nota-se que a intensificação do trabalho, tem levado os trabalhadores a ultrapassarem ou a deixarem de reconhecer os seus próprios limites físicos e mentais, expondo-os aos riscos de adoecimento, cada vez mais frequentes. "Muitas vezes o trabalhador recebe uma demanda que ultrapassa seus limites causando-lhe o estresse. Pessoas que já são vulneráveis e que passam situações de muito estresse podem até sofrer crises de esquizofrenia". (TEIXEIRA, 2007, p. 33)

A prática de intensificação do trabalho pressupõe fazer a mesma coisa mais agilmente, desconsiderando as limitações orgânicas e psíquicas do trabalhador. Assim o processo de intensificação agrava condições de trabalho não só em termos de qualidade da atividade, mas igualmente na qualidade final do produto. Conclui-se ainda que, as grandes empresas só estão interessadas com a produção rápida visando acúmulo de capital, instituindo metas para que os trabalhadores acelerem o ritmo de produção na busca pela comissão (ou sem ela, sob ameaças de desemprego). Por fim, os que não conseguem atingir o sucesso, extrapolam seus limites, e o adoecer psíquico torna-se o fim de um beco sem saída. Os acometidos por estas situações de trabalho são frequentemente identificados com quadros depressivos, nervosismo, abuso de bebidas alcoólicas, transtornos de ansiedade, esgotamento físico e mental (urnout), sintomas sem explicação, todos estes, com profundas consequências para a saúde mental, gerando impactos cada vez maiores nas esferas laboral, social e familiar. Entra em questão que o processo de alienação presente nas metas estabelecidas tem produzido ainda sequelas na concepção de

RC: 97019

Disponível em: https://www.nucleodoconhecimento.com.br/psicologia/intensificacaodo-trabalho 
sofrimento do trabalho, na cabeça dos trabalhadores. De acordo com vários pesquisadores (ASSUNÇÃO e OLIVEIRA, 2014):

\begin{abstract}
Vale ressaltar que o sofrimento no trabalho, associado ao adoecimento em estudos específicos, está sempre ligado a um conflito entre a vontade de bem fazer o seu trabalho, de acordo com as novas regras implícitas da profissão, e a pressão que os leva a certas regras para aumentar a sua produtividade (ASSUNÇÃO e OLIVEIRA, 2014, p. 366).
\end{abstract}

No entanto, no que tange a responsabilidade das organizações empresariais, estas eufemizam as situações de riscos à saúde mental do trabalhador. Assim, em situações que podem submeter a integridade física do trabalhador a riscos, é acionado a estratégia da eufemização e ridicularização. Tais fatos explicam, em parte, a baixa adesão na utilização de equipamentos de proteção individual. "Quando eu tive a crise, acho que foi o esgotamento físico que atingiu o cérebro! Esgotamento físico levou para o esgotamento do sistema nervoso", relatou um trabalhador submetido a tal esquema laboral. (SILVA, 1992, p. 83)

A violência laboral e a submissão a condição do adoecimento mental encontra seu auge em trabalhadores, que expressam temor e assim evitam procurar o médico do trabalho, cujo temor recai na cultura empresarial, sempre presente, de associar a demissão à lista dos que apresentam qualquer distúrbio na saúde mental.

O panorama desenhado por nós, assinala que a intensificação de trabalho expressa nas metas tem se configurado como um processo de violência laboral que causa a vulnerabilização da saúde do trabalhador, entre os transtornos mentais prevalentes nestas situações, podemos destacar: delirium; transtorno cognitivo leve; alcoolismo crônico (relacionado ao trabalho); episódios depressivos; estado de estresse póstraumático, neurastenia (inclui síndrome de fadiga), outros transtornos neuróticos especificados (inclui neurose profissional); transtorno do ciclo vigília-sono e Burnout. A partir disto, podemos concluir que por consequência deste processo violência laboral, que acaba causando o adoecer psíquico, tanto o trabalhador como a família e a sociedade como um todo pagam o preço deste intenso ritmo de trabalho. $\mathrm{O}$ diagnóstico de transtorno mental torna apenas flagrante uma situação que é 
ocultada dentro dos ambientes das organizações empresariais, mas que é cada vez mais frequente face ao crescimento desenfreado da competitiva do mercado, marcado pelas metas de trabalho. (SILVA, 2016)

\section{CONSIDERAÇÕES FINAIS}

Percebe-se que na atualidade a competitividade do mercado tem primado pela desumanização das relações de trabalho frente à intensificação do processo produtivo. Nota-se ainda que são explícitos os exemplos onde são sobrepostas as metas de trabalho sobre as relações humanas e a qualidade de vida. Assim, fica patente que acúmulo de capital e obtenção de vantagens competitivas têm gerido as relações de trabalho. Não raras vezes os trabalhadores se referem à jornada de seu dia no trabalho com expressões "vou pra guerra", "para a batalha" ou "matar o leão do dia", obra, quase oculta, do processo de intensificação do trabalho. Nota-se com esta concepção que as condições e as exigências laborais com metas a serem cumpridas fragilizam o sentido da vida, deixando no trabalhador as marcas do suplício, cujos sintomas têm sido expressos numa vasta gama de doenças ditas ocupacionais, vulnerabilizando a saúde mental. No temor ante a perda do emprego, os trabalhadores acabam por eufemizar seu sofrimento, numa tentativa pífia de evitação do adoecer, por fim, ocasionam o agravamento de sua, já debilitada, condição. A trama que envolve a problemática acaba por explicar a manipulação pelo medo e na luta pela subsistência dos trabalhadores com manutenção do emprego que resulta na resistência a uma jornada excessiva de trabalho, ante a incapacidade, cada vez mais presente, ou insucesso em cumprir as metas, obra das condições insalubres no ambiente laboral que repercutem diretamente na saúde mental do trabalhador. Pesquisas da OMS (PIMENTA, 2021), relatam que o transtorno mental tende a se tornar a principal causa de afastamento do trabalho em todo o mundo. No Brasil, o INSS, no ano de 2011, registra um número de 211 mil pessoas afastadas do ambiente laboral por consequência de doenças mentais. (BERNARDO; NOGUEIRA e BULL, 2014)

RC: 97019

Disponível em: https://www.nucleodoconhecimento.com.br/psicologia/intensificacaodo-trabalho 
Portanto, fica evidente que o cenário exposto inspira cuidados para os colaboradores destas instituições. Professores, consultores, vendedores ou quaisquer ramos atuais que deem conta de negócios comerciais, tendo por base números ou quantitativo de produção a ser atingida, os quais implicam em vencimentos financeiros e, sobretudo, a manutenção do próprio emprego, estão tendentes e intensamente vulneráveis a situações de adoecimento mental.

Nesta direção, como prognóstico deste processo de desumanização do trabalho, intensificação e aceleração do ritmo e produção desenfreada, a sociedade de hoje produzirá uma hoste de indivíduos em intenso processo de sofrimento psíquico e cada vez mais inaptos para as atividades laborais. Destas 211 mil pessoas afastadas do trabalho em 2011, podemos prever um crescimento geométrico assustador nos próximos anos. Em égide não só de um crescimento econômico equilibrado, mas principalmente em relação à saúde mental dos trabalhadores, necessitamos de urgentes medidas trabalhistas que garantam condições de qualidade de vida compatíveis, produzindo um labor salubre, significante e produtivo na vida dos indivíduos, assim, estas estratégias tem sido visto como as vias de escape ao sofrimento.

As condições laborais e as relações sociais entre os trabalhadores, bem como as condições de trabalho influenciam diretamente a qualidade de vida. Portanto, tornase premente e ao mesmo tempo urgente a paulatina, mas progressiva discussão acerca das questões laborais que gravitam na órbita das relações de trabalho na atualidade, sabendo-se que essa estratégia pode não ser apenas uma forma de cuidar da saúde dos trabalhadores, mas também pode vir a garantir a sobrevivência e o desenvolvimento futuros das organizações empresariais.

\section{REFERÊNCIAS}

ASSUNÇÃO, Ada da Ávila; OLIVEIRA, Dalila Andrade. Intensificação do trabalho e saúde dos professores. Educ. Soc., Campinas, v. 30, n. 107, Aug. 2009. Disponível em <http://www.scielo.br/scielo.php?script=sci_arttext\&pid=S0101- 
73302009000200003\&lng=en\&nrm=iso>. Acessado em 14 de junho de 2014. http://dx.doi.org/10.1590/S0101-73302009000200003.

BERNARDO, Marcia Hespanhol; NOGUEIRA, Francisco Ronald Capoulade; BULL, Sandra. Trabalho e saúde mental: repercussões das formas de precariedade objetiva e subjetiva. Arq. bras. psicol., Rio de Janeiro, v. 63, n. spe, 2011. Disponível em <http://pepsic.bvsalud.org/scielo.php?script=sci_arttext\&pid=S1809 $52672011000300009 \&$ Ing=pt\&nrm=iso >. Acesso em 14 de junho de 2014.

CAMELO, Silvia Helena Henriques; ANGERAMI, Emília Luigia Saporiti. Riscos psicossociais no trabalho que podem levar ao estresse: uma análise da literatura. Cienc Cuid Saude 2008 Abr/Jun; 7(2):232-240.

CHAPLIN, Charles. Filme: Tempos modernos. EUA, 1936.

CLOT, Yves. Travail et pouvoir d'agir. Paris: PUF, 2008.

DEJOURS, Christophe. (1994). A loucura do trabalho. São Paulo: Oboré.

FOUCAULT, Michel. Vigiar e punir: nascimento da prisão. Trad. Lígia M. Pondé Vassalto. Petrópolis: Vozes, 1987.

FRANCO, Tânia; DRUCK, Graça; SELIGMANN-SILVA, Edith. As novas relações de trabalho, o desgaste mental do trabalhador e os transtornos mentais no trabalho precarizado. Rev. bras. saúde ocup., São Paulo, v. 35, n. 122, Dec. 2010. Disponível em <http://www.scielo.br/scielo.php?script=sci_arttext\&pid=S030376572010000200006\&lng=en\&nrm=iso>. - Acesso 14 de junho de 2014. http://dx.doi.org/10.1590/S0303-76572010000200006.

HELOANI, José Roberto; CAPITÃO, Cláudio Garcia. Saúde mental e psicologia do trabalho. São Paulo Perspec., São Paulo, v. 17, n. 2, Junho de 2003. Disponível em $<$ http://www.scielo.br/scielo.php?script=sci_arttext\&pid=S0102- 
$88392003000200011 \& \operatorname{lng}=$ en\&nrm=iso $>$. Acessado em 14 de junho de 2010. http://dx.doi.org/10.1590/S0102-88392003000200011.

LALLEMENT, Michel. Temps, travail et modes de vie. Paris: PUF, 2003.

LINHART, Danièle. (2009). Modernisation et précarisation de la vie au travail. Papeles del CEIC (Centro de Estudios sobre la Identidad Colectiva), (49). Disponível em <www.identidadecolectiva.es/pdf/43.pdf $>$ - Acessado em 01 de novembro de 2012.

PIMENTA, Tatiana. Saúde mental no ambiente de trabalho. Disponível em $<$ https://www.vittude.com/empresas/saude-mental-no-ambiente-de-trabalho> Acesso dia 06 de julho de 2021.

POTER, Michael. Vantagem competitiva: criando e sustentando um desempenho superior.Rio de Janeiro: Elsevier, 1989.

SENNETT, Richard. A corrosão do caráter: consequências pessoais do trabalho no novo capitalismo. São Paulo: Record, 1999.

SILVA, Edith Seligmann. A inter-relação trabalho-saúde mental: um estudo de caso. Rev. adm. empres., São Paulo, v. 32, n. 4, Oct. 1992 . Disponível em $<$ http://www.scielo.br/scielo.php?script=sci_arttext\&pid=S0034 75901992000400007\&lng=en\&nrm=iso>. Acessado em 14 de junho de 2016. http://dx.doi.org/10.1590/S0034-75901992000400007.

SILVA, Edith Seligmann. A inter-relação trabalho-saúde mental: um estudo de caso. Rev. adm. empres., São Paulo, v. 32, n. 4, Oct. 1992 . Disponível em $<$ http://www.scielo.br/scielo.php?script=sci_arttext\&pid=S003475901992000400007\& Ing=en\&nrm=iso >. Acesso em 14 de junho de 2014. http://dx.doi.org/10.1590/S0034 75901992000400007. 
TEIXEIRA, Sueli. A depressão no meio ambiente do trabalho e sua caracterização como doença no trabalho. in: Rev. Trib. Reg. Trab. 3르 Reg., Belo Horizonte, v.46, n.76, p.27-44, jul./dez.2007.

VENCO, S. Quando o trabalho adoece: uma análise sobre o teleatendimento. INTERFACEHS - Revista de Gestão Integrada em Saúde do Trabalho e Meio Ambiente - v.3, n.3, Artigo 1, Ago./ dez 2008.

\section{APÊNDICE - REFERÊNCIA NOTA DE RODAPÉ}

3. O stalinismo, em síntese, daria conta da exploração da classe trabalhadora e produzindo o acúmulo de benefícios, capital e privilégios à custa da classe trabalhadora.

4. O termo é empregado por Karl Marx, se discutindo a diferença entre o valor final da mercadoria produzida e a soma do valor dos meios de produção e do valor laboral, que seria a base do lucro no capitalismo.

5. Presenteísmo se refere à presença física e ausência mental, expressa no a estar presente fisicamente, mas sem ação e comprometimento.

6. A violência do ambiente laboral, refere-se a perspectiva de Dejours (1994), quando este aborda, entre outras questões, o assédio moral sofrido pelos trabalhadores, muitas vezes, ante a incapacidade de cumprir metas.

7. Para Foucault (1987) consiste na utilização do corpo humano como um instrumento de expressão de poder. Fazendo do corpo humano simplesmente um objeto ou coisa qualquer. No que tange às relações humanas, o conceito se refere à superficialização e robotização do humano.

Enviado: Dezembro, 2020.

Aprovado: Setembro, 2021.

RC: 97019

Disponível em: https://www.nucleodoconhecimento.com.br/psicologia/intensificacaodo-trabalho 